\title{
Synergistic Effect of Anthropogenic Disturbances on Offspring Demography of Pentadesma butyracea (Clusiaceae), a Threatened Tree Species in Benin (West-Africa)
}

\author{
M'Mouyohoun Kouagou1, Olivier E. B. Ahouandjinou', Laurent Houessou, ${ }^{1,2}$, Aliou Dicko1*, \\ Armand Kuyema Natta1,2
}

${ }^{1}$ Laboratory of Ecology, Botany and Plant Biology, Parakou, Republic of Benin

${ }^{2}$ Faculty of Agronomy, University of Parakou, Parakou, Republic of Benin

Email: *dicko_aliou@yahoo.fr

How to cite this paper: Kouagou, M., Ahouandjinou, O.E.B., Houessou, L., Dicko, A. and Natta, A.K. (2019) Synergistic Effect of Anthropogenic Disturbances on Offspring Demography of Pentadesma butyracea (Clusiaceae), a Threatened Tree Species in Benin (West-Africa). American Journal of Plant Sciences, 10, 1374-1390. https://doi.org/10.4236/ajps.2019.108098

Received: June 24, 2019

Accepted: August 23, 2019

Published: August 26, 2019

Copyright $\odot 2019$ by author(s) and Scientific Research Publishing Inc. This work is licensed under the Creative Commons Attribution International License (CC BY 4.0).

http://creativecommons.org/licenses/by/4.0/

\begin{abstract}
Understanding how ecological differences and anthropogenic disturbances synergistically drive population dynamics decline is critical for optimal management strategy definition. Main anthropogenic disturbances such as habitat size reduction, fire and non-timber forest harvest affect demographic processes but our understanding of their interaction effects in contrasted ecological conditions is limited. We investigated the interaction effects of fruit harvest, fire, gallery forest size and distance to streambed on density, recruitment, survival and growth of Pentadesma butyracea offspring in dry and moist ecological conditions. We randomly selected in each ecological region six $P$. butyracea populations. We then established in each population, 10 subplots of $100 \mathrm{~m}^{2}$ within 1 ha to assess offspring demographic performance from 2015 to 2017. Results showed that fire suppressed the positive effect of large habitat size and amplified the negative effect of increasing local aridity on offspring growth. Fire and harvest synergistically reduced growth whereas offspring growth was resilient to fire in moist ecological region. Moist ecological conditions mitigated the negative effect of harvest on growth. Harvest mitigated the surprise negative effect of large habitat size on survival. However, in large gallery size, high harvest limited clonal recruitment and growth. There was a positive interaction effect between harvest and distance to streambed on survival (High harvest, $\mathrm{Z}=2.045, \mathrm{p}=0.041$, Medium, $\mathrm{Z}=2.060, \mathrm{p}=0.039$ ) but a negative interaction effect on growth (High, $t=-2.357, p<0.05$, Medium, $t=$ $-1.403, \mathrm{p}>0.05)$. Clonal offspring grew faster than sexual offspring in high
\end{abstract}


harvest populations. In moist region, offspring survived better in large gallery forest size. In 2017, survival and growth were lower in large gallery forest. In 2017, offspring growth was higher near the riverbed where the survival rate low. This study suggests that management strategies should consider the interaction effects of anthropogenic disturbances and climatic conditions.

\section{Keywords}

Fire, Habitat Size Reduction, Multiple Stressors, Pentadesma butyracea, Survival-Growth Trade-Off

\section{Introduction}

Tropical forests are facing several anthropogenic and natural pressures causing species population decline and extinction. Anthropogenic pressures include land clearing for agriculture, harvest of timbers and non-timber forest products, fire, invasive species, grazing [1] and natural disturbances include wind, soil erosion, tree and branch falls, flooding [2]. Anthropogenic and natural disturbances lead to the fragmentation of forest ecosystems, which increased edge effects [3]. They modify the forest fragment microclimate by reducing moisture and increasing the illumination [4], which stimulates the proliferation of the invasive herbaceous. This microclimate increases sensitivity of forest fragments to fire [5].

Fire burns low strata of vegetation and the bark of the trunks [6]. Despite the importance of fire for sustainable management of forest ecosystems in promoting the floristic diversity maintenance [7], it can also be a cause of the biodiversity loss [7] [8]. High fire intensity can reduce seedling and sapling survival [9], [10] and growth [9] [11] [12]. Additionally, recurrent harvest of non-timber forest products can drive plant population decline over time [13]. This harvest often takes place in context of multiple sources of anthropogenic disturbances such as habitat size reduction [14], invasion [1], herbivory [15], fire and herbivory [16] [17] and in contrasted ecological conditions [13] [18]. Human disturbances can act synergetically. For instance, grazing mitigated the high harvest of palm leaf [16]. Habitat fragmentation reduces fragment size and increases fragment isolation [3] [19]. Smaller fragment favors high light penetration into the fragment which in turn favors grasses development in the understory and increases fire frequency in the forests [20].

The effect of anthropogenic disturbances on population demography can be independent, additive or interactive [16] [17]. Fire and habitat size reduction can interact to reduce regeneration density [21]. Worst environmental conditions and pressures due to fire [22] or harvest [18] can synergistically reduce population demography. The harvest of bark and leaves in dry regions can limit fruit production [23]. Worst ecological conditions reduced offspring survival and prevented their growth [13] [18]. Interaction between habitat size reduction and 
harvest can synergistically affect tree demography [24] Water limitation may also affect offspring demography for species of particular ecosystems, such as gallery forest. Low water availability can, for instance, reduce plant establishment [25].

Vegetative reproduction is common among flowering plants. It may be essential to the persistence of the plant species population, especially in environments where sexual reproduction is unpredictable [26]. Moisture conditions can favor plant asexual reproduction [27]. The vegetative offspring growth may vary according to the environmental regime [28]. Vegetative offspring are more robust, grow faster [29] and contribute to the population growth rate than sexual offspring [26]. All these advantages of clonal offspring are due to the maternal effect [30] at the early development stage. Unfortunately, they are sensitive to the stochastic change due to human or natural disturbances because they are genetically identical.

Several tree species of gallery forests are threatened with high risk of extinction in Benin [31]. These species include Pentadesma butyracea, which fruits of $P$. butyracea are heavily harvested by local people to extract seed either for selling or making butter [32]. Heavy harvest of fruit of $P$. butyracea reduced regeneration density [32] and reduced their population dynamics [33]. P. butyracea fruits overexploitation increased density of individual originated from root [14]. This study evaluated the synergistic effects of fire, distance between offspring location in gallery forest and riverbed, gallery forest width and fruit harvest on density, survival and growth of Pentadesma butyracea offspring.

\section{Materials and Methods}

\subsection{Study Design}

We investigated $P$. butyracea offspring demographic response to multiple stressors in the Republic of Benin $\left(6^{\circ}-12^{\circ} 50^{\circ} \mathrm{N}\right.$ and $\left.1^{\circ}-3^{\circ} 40^{\circ} \mathrm{E}\right)$ in West Africa. The Republic of Benin, locates in the "Dahomey Gap", covers $114,763 \mathrm{~km}^{2}$ with 87.2 inhabitants per $\mathrm{km}^{2}$ [34]. Climate is generally dry with Guineo-Congolian region $\left(6^{\circ}-7^{\circ} 30^{\prime} \mathrm{N}\right)$, Sudano-Guinean region $\left(7^{\circ} 30^{\prime}-9^{\circ} 30^{\prime} \mathrm{N}\right)$ and Sudanian region $\left(9^{\circ} 30^{\prime}-12^{\prime} \mathrm{N}\right)$. Our study was conducted in these last two regions (Figure 1), where $P$. butyracea occurs in gallery forests [33]. The average annual rainfall varies between 900 (Sudanian) and $1300 \mathrm{~mm}$ (Guineo-Congolian). The Sudanian (dry) region is characterized by a unimodal rainfall with a rainfall ranging between $900-1100 \mathrm{~mm}$ and an average annual temperature between $24^{\circ} \mathrm{C}$ $31^{\circ} \mathrm{C}$ and is drier than Sudano-Guinean (moist) region with an average rainfall and an average temperature of $1100-1300 \mathrm{~mm}, 25^{\circ} \mathrm{C}-29^{\circ} \mathrm{C}$ respectively [35].

In 2012, we first surveyed all main riverbed and dense forest in the sudanian (dry) and sudano-guinean (moist) regions to record Pentadesma butyracea occurence. At the end of this step, we found 105 sites. Some sites were too closed $(<500 \mathrm{~m})$. After that, we grouped closed sites to get 25 populations in 

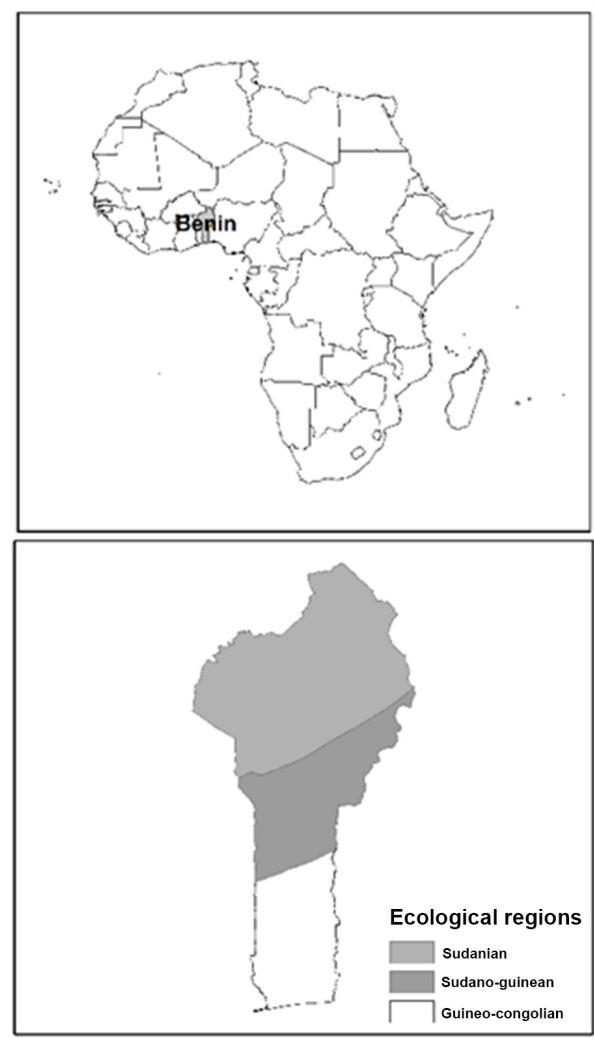

Figure 1. Study area and populations.

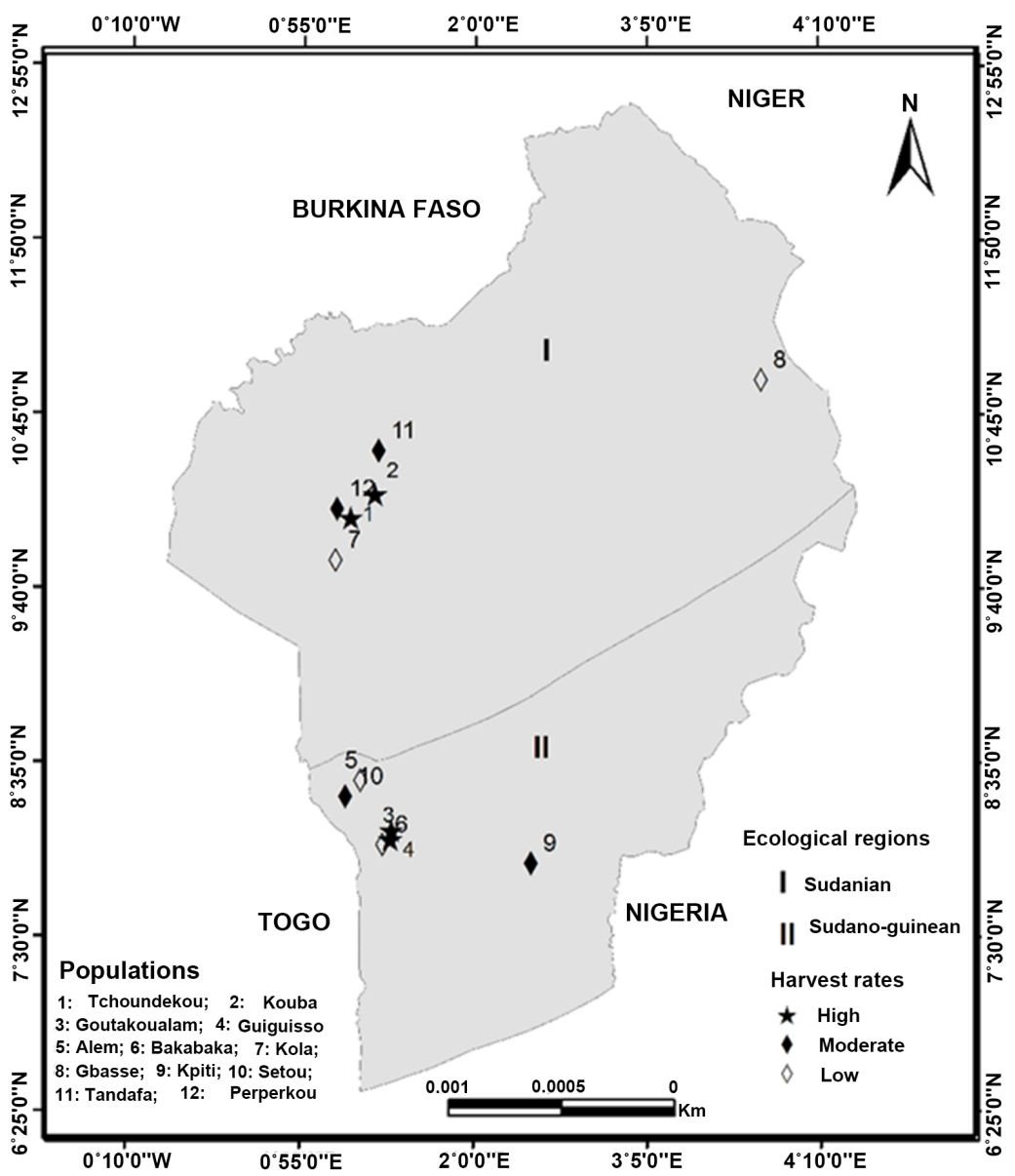

sudano-guinean region and 35 populations in Sudanian region. Finally, we categorized 60 populations into three groups based on harvest intensity (low, medium and high) within each of the two ecological regions. Fruit collectors often remove the seeds from the fruits and drop the empty pericarp underneath mother trees so that the number of empty pericarps is the number of harvested fruits [14]. Then, we estimated the number of entire fruits on the forest floor and visually count the number of fruits on each mature tree in June after maturity season as the fruits that have not been removed by collectors. Fruit harvest intensity was estimated as the proportion of total fruits removed from the population [14]. From this set of populations, we randomly selected two populations per region with low harvest intensity $(0 \%-25 \%)$, two with medium harvest intensity $(25 \%-75 \%)$ and two with high harvest intensity $(75 \%-100 \%)$. Intensity of fruit harvest was evaluated by rating the number of fruit harvested by local people over the total fruit produced by a given population. In 2015, we established 1-ha plots in each population and revisited yearly in 2016 and 2017. We tagged all adult using round, numbered aluminum tags and measured each individual size annually. We replaced lost tags at the beginning of each yearly census. 


\subsection{Offspring Demography}

In each population, we established 10 subplots of $100 \mathrm{~m}^{2}$ each within 1 ha. In each quadrat, we monitored all $P$. butyracea individuals with $\mathrm{dbh} \leq 2 \mathrm{~cm}$ (offspring) from 2015 to 2017 for their density, survival and growth and for new individual recruitment. The presence or not of fire within subplots was noted at each census. We measured at each census the diameter at base of each individual, the distance from individual to the streambed and the average gallery forest width. In 2016 and 2017 we recorded diameter at base of all alive individual tagged in 2015 and 2016. At the same time, we also recorded diameter at base and reproductive strategy of new born offspring called recruitment. Newly recruited offspring were defined as those that had not been found in a previous census and had a diameter $\leq 1 \mathrm{~cm}$ and a height $\leq 0.5 \mathrm{~m}$ [20]. We recorded the reproduction strategy (vegetative or seed) for each individual digging under each offspring to check if the offspring root was linked to another bigger root for vegetative originated offspring nor not for seed originated offspring.

\subsection{Data Analysis}

To test the effect of ecological differences, fruit harvest, fire, reproduction mode (only for survival and growth), gallery forest width and the distance to the riverbed and year on density, clonal ratio and survival of offspring generalized linear mixed effect models were used [36] with the package glmmTMB [37]. For offspring growth, we used lme4 package [38]. The Akaike Information Criterion (AIC) was used to compare models [39]. $\triangle \mathrm{AIC}=\mathrm{AIC}_{\mathrm{i}}-\mathrm{AIC}_{\text {min }}$ is the difference between the AIC of a model given i and the smallest AIC. Models with a $\triangle$ AIC < 2 are all plausible, $4-7$ are considerably less plausible and $\Delta$ AIC $>10$ means that the models lack some important explanatory variables [39].

Total offspring density and density of offspring recruitment were modeled constructing 25 models. We used generalized Poisson, negative binomial and Poisson distributions. We chose the Poisson distribution for offspring density and negative binomial for recruitment density as the bests. Clonal ratio was modeled constructing 22 models using beta regression [40]. Offspring survival and relative growth rate were modeled constructing 29 models using binomial distribution for survival and Gaussian distribution for growth. Best model had $\triangle \mathrm{AIC} \leq 2$ and more predictors. In all models, subplot was nested within population as random component while only two ways interactions were included in full models. All analyses were performed with the statistical software $\mathrm{R}$ version 3.4.1 [41].

\section{Results}

\subsection{Effect of Harvest, Fire, Gallery Width, the Distance to the Riverbed on Density, Clonal Ratio and Offspring Recruitment}

The variance of density due the random selection of populations was $\sigma^{2}=0.089$ and the random establishment of subplot within population was $\sigma^{2}=0.748$. Fire 
favored offspring density ( $\beta_{\text {Burned vs Unburned }}=0.217 \pm 0.109, \mathrm{Z}=1.993, \mathrm{p}=0.046$, Table 1) but this effect varied among years (Figure 2(a)). For example, fire prevented offspring establishment by reducing their density in $2016\left(\beta_{\text {Burned:2016 }}=\right.$ $-0.366 \pm 0.084, \mathrm{Z}=-4.342, \mathrm{p}<0.0001$, Figure $2(\mathrm{a}))$ and $2017\left(\beta_{\text {Burned:2017 }}=\right.$ $-0.653 \pm 0.094, Z=-6.913, p<0.0001$, Figure $2(a))$. This may be due to the reduction of density in $2016\left(\beta_{2015 \text { vs } 2016}=-0.167 \pm 0.059, Z=-2.819, \mathrm{p}=0.005\right.$, Table 1) and $2017\left(\beta_{2015 \text { vs } 2017}=-0.237 \pm 0.061, \mathrm{Z}=-3.897, \mathrm{p}<0.0001\right.$, Table 1$)$ compared with 2015 (Figure 2(a)).

The variance of clonal ratio was near zero $\left(\sigma^{2}=2.051 \mathrm{e}-09\right)$ among populations and was $\sigma^{2}=0.045$ within populations. High and medium fruit harvest significantly increased clonal ratio $\left(\beta_{\text {Low vs Medium }}=0.65 \pm 0.175, \mathrm{Z}=3.708, \mathrm{p}=\right.$ $0.0002 ; \beta_{\text {Low vs High }}=0.677 \pm 0.175, Z=3.874, \mathrm{p}=0.0001$, Table 2, Figure 2(b)) Clonal ratio was higher in $2016\left(\beta_{2015 \text { vs. } 2016}=0.794 \pm 0.151, Z=5.267, p<0.0001\right.$, Table 2$)$ and $2017\left(\beta_{2015 \text { vs } 2017}=0.393 \pm 0.145, \mathrm{Z}=2.706, \mathrm{p}=0.007\right.$, Table 2,

Table 1. Effect of fire, gallery width, distance to the riverbed, ecological region and fruit harvest on density of $P$. butyracea offspring from 2015 to 2017 (summary of the best model).

\begin{tabular}{|c|c|c|c|c|}
\hline Variables & $\beta$ & SE & $\mathrm{Z}$ & $\mathrm{P}$ \\
\hline Intercept & 3.106 & 0.417 & 7.444 & $\mathrm{p}<0.0001^{* * *}$ \\
\hline Moist region & $0.313 \mathrm{~F}$ & 0.420 & 0.745 & 0.456 \\
\hline Medium harvest & 0.033 & 0.34 & 0.098 & 0.9221 \\
\hline High harvest & -0.302 & 0.553 & -0.545 & 0.585 \\
\hline Burned & 0.217 & 0.109 & 1.993 & $0.046^{*}$ \\
\hline 2016 & -0.167 & 0.059 & -2.819 & $0.005^{* *}$ \\
\hline 2017 & -0.237 & 0.061 & -3.897 & $\mathrm{p}<0.0001^{* * *}$ \\
\hline Habitat size & 0.726 & 0.482 & 1.507 & 0.132 \\
\hline Distance to riverbed & -0.545 & 0.38 & -1.436 & 0.151 \\
\hline Moist region $\times$ Burned & -0.129 & 0.127 & -1.01 & 0.312 \\
\hline Moist region $\times$ Habitat size & -0.424 & 0.529 & -0.802 & 0.423 \\
\hline Medium harvest $\times$ Habitat size & -0.231 & 0.524 & -0.441 & 0.659 \\
\hline High harvest $\times$ Habitat size & 0.639 & 1.067 & 0.598 & 0.55 \\
\hline Medium harvest $\times$ Distance to riverbed & 0.612 & 0.37 & 1.656 & 0.098 \\
\hline High harvest $\times$ Distance to riverbed & 0.112 & 0.506 & 0.221 & 0.825 \\
\hline Burned $\times 2016$ & -0.366 & 0.084 & -4.342 & $\mathrm{p}<0.0001^{* * *}$ \\
\hline Burned $\times 2017$ & -0.653 & 0.094 & -6.913 & $\mathrm{p}<0.0001^{* * *}$ \\
\hline $2016 \times$ Distance to riverbed & -0.073 & 0.041 & -1.773 & 0.076 \\
\hline $2017 \times$ Distance to riverbed & -0.074 & 0.042 & -1.777 & 0.076 \\
\hline Habitat size $\times$ Distance to riverbed & 0.076 & 0.173 & 0.437 & 0.662 \\
\hline
\end{tabular}

Note: $\beta, \mathrm{SE}, \mathrm{Z}$ and $\mathrm{CI}$ were the estimate, the standard error, the Wald statistic and the associated $\mathrm{p}$-value respectively. Asterisks show significant level: ${ }^{\star} \mathrm{p}<0.05 ;{ }^{* *} \mathrm{p}<0.01 ;{ }^{* *} \mathrm{p}<0.001$. 
Table 2. Effect of fire, gallery width, distance to the riverbed, ecological region and fruit harvest on clonal proportion of P. butyracea 2015 and 2017 (summary of the best model).

\begin{tabular}{ccccc}
\hline Variables & $\beta$ & $\mathrm{SE}$ & $\mathrm{Z}$ & $\mathrm{P}$ \\
\hline Intercept & $\mathbf{1 . 3 8 7}$ & $\mathbf{0 . 1 7 0}$ & $\mathbf{8 . 1 4 8}$ & $\mathrm{p}<0.0001^{* * *}$ \\
Moist region & -0.210 & 0.173 & -1.218 & 0.223 \\
Medium harvest & $\mathbf{0 . 6 5 0}$ & $\mathbf{0 . 1 7 5}$ & $\mathbf{3 . 7 0 8}$ & $\mathbf{0 . 0 0 0 2 ^ { * * * }}$ \\
High harvest & $\mathbf{0 . 6 7 7}$ & $\mathbf{0 . 1 7 5}$ & $\mathbf{3 . 8 7 4}$ & $\mathbf{0 . 0 0 0 1 ^ { * * * }}$ \\
Burned & 0.112 & 0.138 & 0.809 & 0.418356 \\
2016 & $\mathbf{0 . 7 9 4}$ & $\mathbf{0 . 1 5 1}$ & $\mathbf{5 . 2 6 7}$ & $\mathrm{p}<0.0001^{* * *}$ \\
2017 & $\mathbf{0 . 3 9 3}$ & $\mathbf{0 . 1 4 5}$ & $\mathbf{2 . 7 0 6}$ & $\mathbf{0 . 0 0 7 ^ { * * }}$ \\
Habitat size & -0.052 & 0.1 & -0.523 & 0.601 \\
Distance to riverbed & 0.043 & 0.082 & 0.526 & 0.599 \\
\hline
\end{tabular}

Note: $\beta, \mathrm{SE}, \mathrm{Z}$ and $\mathrm{CI}$ were the estimate, the standard error, the Wald statistic and the associated $\mathrm{p}$-value respectively. Asterisks show significant level: ${ }^{* *} \mathrm{p}<0.01 ;{ }^{* * *} \mathrm{p}<0.001$.

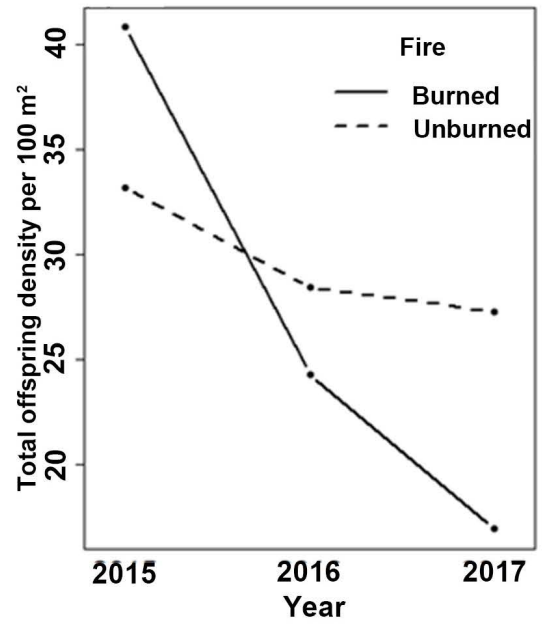

(a)

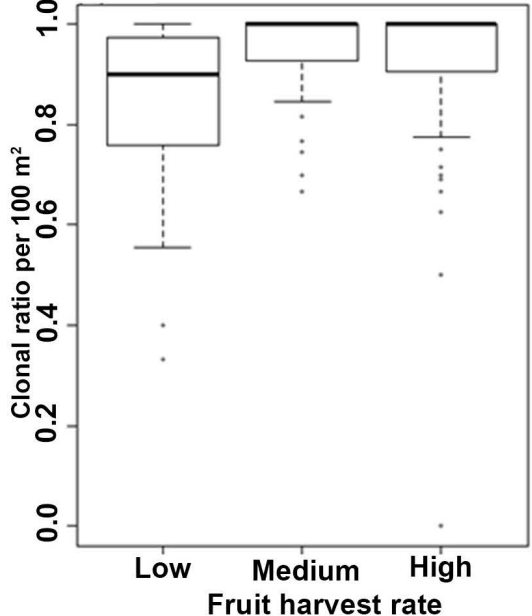

(b)

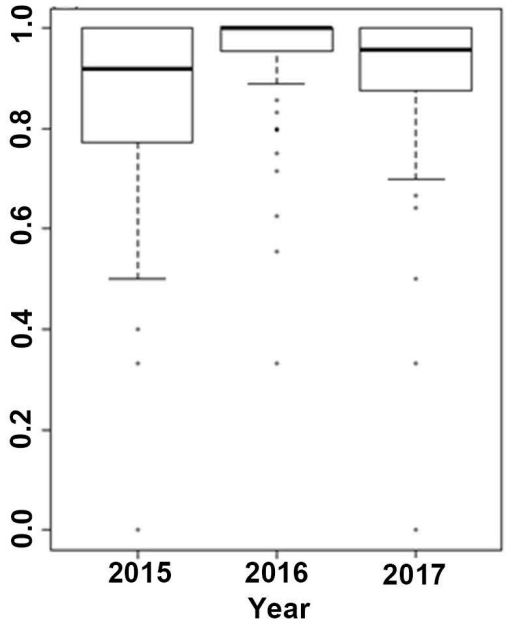

(c)

Figure 2. Effect of fire (Burned vs. unburned), fruit harvest (low, medium and high) and year (2015, 2016 and 2017) on density (a), clonal ratio (b) and (c) of $P$. butyracea offspring. Values are estimate \pm 1 S.E. Asterisks on the figure show significant differences ${ }^{* *} \mathrm{p}<0.01 ;{ }^{* *} \mathrm{p}<0.001$.

Figure 2(c)). The variance of the new born density among populations was $\sigma^{2}=$ 0.187 and within population was near zero $\left(\sigma^{2}=2.084 \mathrm{e}-08\right)$. However, there was no significant effect of anthropogenic disturbances and ecological differences on new born density. Indeed, there was no model with $\Delta \mathrm{AIC} \leq 2$ containing predictor.

However, fruit harvest reduced clonal recruitment in high $\left(\beta_{\text {Low vs High }}=-0.834\right.$ $\pm 0.317, \mathrm{Z}=-2.635, \mathrm{p}=0.008$, Table 3, Figure $3(\mathrm{a})$ ) but not in medium harvest populations $\left(\beta_{\text {Low vs Medium }}=-0.091 \pm 0.229, Z=-0.398, P=0.691\right.$, Table 3$)$. High fruit in large gallery significantly reduced clonal recruitment $\left(\beta_{\text {Habitat sizexHigh harvest }}=\right.$ $-1.43 \pm 0.427, \mathrm{Z}=-3.345, \mathrm{p}=0.0008$, Table 3, Figure $3(\mathrm{a})$ ). The variances of 
Table 3. Effect of fire, gallery width, distance to the riverbed, ecological region, mode of reproduction and fruit harvest on new born clonal ratio of $P$. butyracea between 2016 and 2017 (summary of the best model).

\begin{tabular}{|c|c|c|c|c|}
\hline Variables & $\beta$ & SE & $\mathrm{Z}$ & $\mathrm{P}$ \\
\hline Intercept & 3.772 & 0.376 & 10.033 & $\mathrm{p}<0.0001^{* * *}$ \\
\hline Moist region & 0.302 & 0.344 & 0.88 & 0.379 \\
\hline Medium harvest & -0.091 & 0.229 & -0.398 & 0.691 \\
\hline High harvest & -0.834 & 0.317 & -2.635 & $0.008^{* *}$ \\
\hline Burned & -0.132 & 0.183 & -0.722 & 0.47 \\
\hline 2017 & 0.074 & 0.271 & 0.271 & 0.786 \\
\hline Habitat size & 0.149 & 0.338 & 0.442 & 0.658 \\
\hline Distance to riverbed & 0.355 & 0.200 & 1.777 & 0.0766 \\
\hline Moist region $\times 2017$ & -0.097 & 0.391 & -0.248 & 0.804 \\
\hline Moist region $\times$ Habitat size & -0.262 & 0.366 & -0.716 & 0.474 \\
\hline Medium harvest $\times$ Habitat size & -0.531 & 0.29 & -1.833 & 0.067 \\
\hline High harvest $\times$ Habitat size & -1.43 & 0.427 & -3.345 & $0.0008^{* * *}$ \\
\hline $2017 \times$ Habitat size & 0.135 & 0.217 & 0.622 & 0.534 \\
\hline $2017 \times$ Distance to riverbed & -0.392 & 0.203 & -1.934 & 0.053 \\
\hline Habitat size $\times$ Distance to riverbed & -0.549 & 0.116 & -4.738 & $\mathrm{p}<0.0001^{* * *}$ \\
\hline
\end{tabular}

Note: $\beta, \mathrm{SE}, \mathrm{Z}$ and $\mathrm{CI}$ were the estimate, the standard error, the Wald statistic and the associated $\mathrm{p}$-value respectively. Asterisks show significant level: ${ }^{* *} \mathrm{p}<0.001$.

new clonal ratio among populations $\left(\sigma^{2}=2.874 \mathrm{e}-11\right)$ and within populations $\left(\sigma^{2}\right.$ $=1.393 \mathrm{e}-09)$ were both near zero.

\subsection{Synergistic Effect of Gallery Forest Size, Fire, Fruit Harvest, Reproduction Mode and Ecological Region on Offspring Survival}

The variance of survival among populations was very low and near zero $\left(\sigma^{2}=\right.$ $8.047 \mathrm{e}-09)$ but higher within population $\left(\sigma^{2}=0.879\right)$. Large gallery forest in moist region favored high survival than small gallery forest size $(\beta=3.344 \pm$ $0.839, \mathrm{Z}=3.985, \mathrm{p}<0.0001$, Figure $3(\mathrm{~b})$ ). Offspring survived better in high harvest population $\left(\beta_{\text {Low vs high }}=8.337 \pm 2.559, \mathrm{Z}=3.259, \mathrm{p}=0.001\right.$, Figure $\left.3(\mathrm{~b})\right)$ than in medium and in low harvest populations $\left(\beta_{\text {Low vs Medium }}=0.39 \pm 0.952, \mathrm{Z}=\right.$ $0.410, \mathrm{p}=0.682)$. Survival was low in medium $(\beta=-0.824 \pm 0.266, \mathrm{Z}=-3.096, \mathrm{p}$ $=0.002)$ and in high $(\beta=-0.743 \pm 0.271, \mathrm{Z}=-2.742, \mathrm{p}=0.006)$ harvest population in 2017. As expected, high harvest in large gallery forest size improved offspring survival $(\beta=7.592 \pm 2.005, \mathrm{Z}=3.787, \mathrm{p}=0.0002$, Figure $3(\mathrm{~b}))$. Surprisingly, in high $(\beta=1.079 \pm 0.527, \mathrm{Z}=2.045, \mathrm{p}=0.041$, Figure $3(\mathrm{~b}))$ and me$\operatorname{dium}(\beta=0.616 \pm 0.299, \mathrm{Z}=2.060, \mathrm{p}=0.039$, Figure $3(\mathrm{~b}))$ harvest population offspring located far from the streambed had high survival than those located 


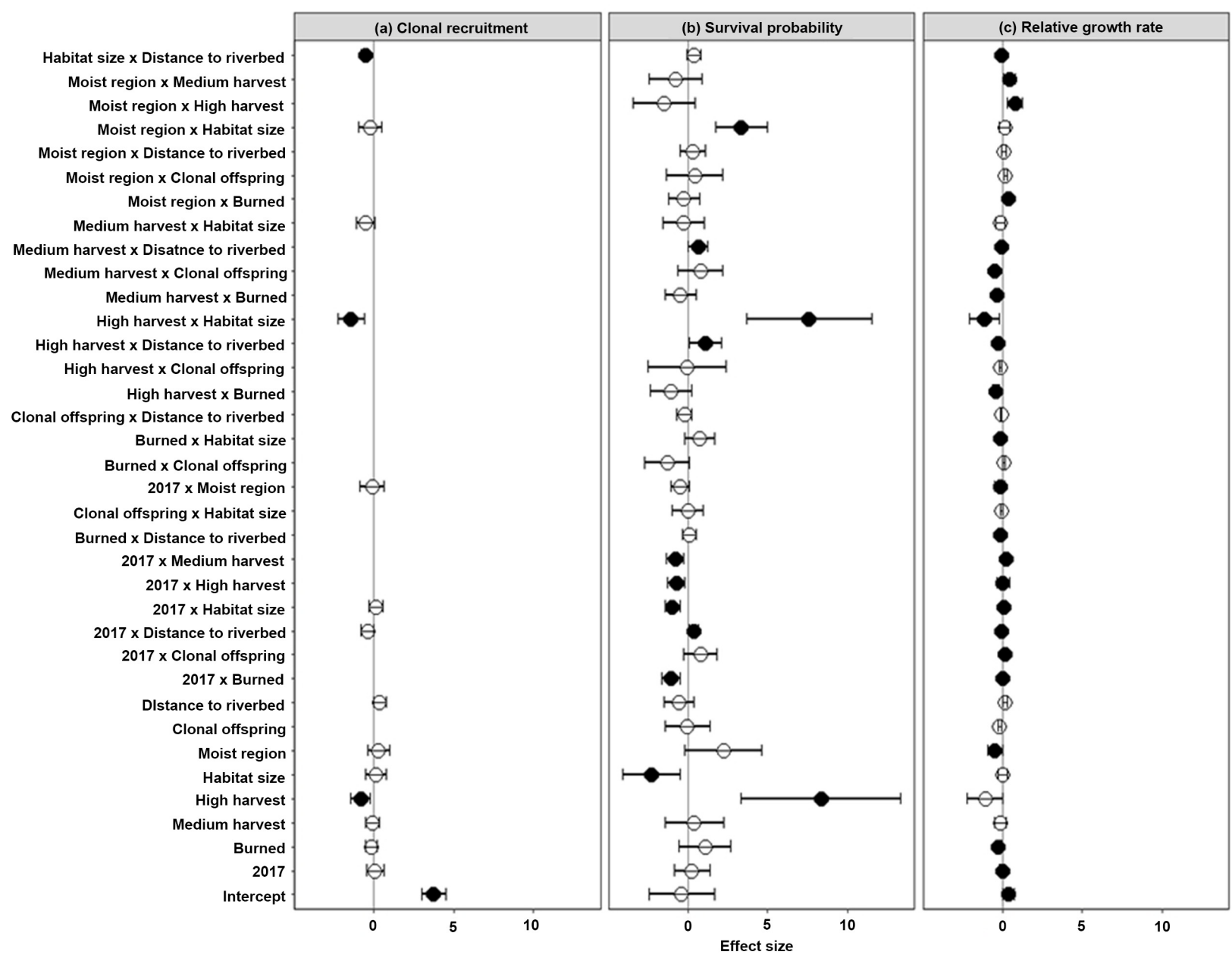

Figure 3. Effect of fire (Burned vs. unburned), habitat size (gallery width), fruit harvest (low, medium and high), reproduction strategy (clonal vs. sexual) and the distance to the riverbed on clonal recruitment (a), survival (b) and relative growth rate (c) of $P$. butyracea offspring. Filled circles show information on significant predictors and unfilled circles show no significant effect.

near the streambed. Moreover, over years, offspring located far from the streambed had high survival $\left(\beta_{2017 \times \text { Distance to river }}=0.35 \pm 0.148, \mathrm{Z}=2.373, \mathrm{p}=0.018\right.$, Figure $3(\mathrm{~b}))$. The effect of fire on survival was year dependent $\left(\beta_{\text {Burned } \times 2017}=-1.079 \pm\right.$ $0.298, \mathrm{Z}=-3.627, \mathrm{p}=0.0003$, Figure $3(\mathrm{~b}))$. Offspring originated from seed were surprisingly marginally resilient to fire than clonal offspring $\left(\beta_{\text {Burned } \times \text { clonal offspring }}=\right.$ $-1.326 \pm 0.723, Z=-1.835, p=0.066$, Figure $3(b))$. Contrary to our expectation, offspring survival was higher in small gallery forest size than in large gallery forest size $\left(\beta_{\text {Habitat size }}=-2.325 \pm 0.911, \mathrm{Z}=-2.553, \mathrm{p}=0.011\right.$, Figure $\left.3(\mathrm{~b})\right)$. This was consistent over years $\left(\beta_{2017 \times \text { Habitat size }}=-0.982 \pm 0.231, \mathrm{Z}=-4.254, \mathrm{p}<0.0001\right.$, Figure 3(b)).

\subsection{Gallery Forest Width, Fire, Fruit Harvest and Distance to Riverbed Synergistically Affected Offspring Growth}

The variance of relative growth rate was higher within population $\left(\sigma^{2}=0.056\right)$ than among populations $\left(\sigma^{2}=0\right)$. Offspring relative growth rate was higher in dry region than in moist $\left(\beta_{\text {Dry vs Moist }}=-0.476 \pm 0.24, \mathrm{Z}=-1.986\right.$, Figure $3(\mathrm{c})$ ). 
Moist ecological region mitigated the negative effect of harvest ( $\beta_{\text {Moist } \times \text { Medium Harvest }}$ $=0.449 \pm 0.196, Z=2.290 ; \beta_{\text {Moist } \times \text { High Harvest }}=0.780 \pm 0.227, Z=3.435$, Figure $3(\mathrm{c}))$, fire $\left(\beta_{\text {Moist } \times \text { Burned }}=0.35 \pm 0.084, Z=4.193\right.$, Figure $\left.3(c)\right)$ and of annual variation $\left(\beta_{\text {Moist } \times 2017}=0.181 \pm 0.046, Z=3.961\right)$ on offspring growth. Fire significantly reduced offspring growth $\left(\beta_{\text {Burned vs Unburned }}=-0.262 \pm 0.095, Z=2.770\right.$, Figure $3(\mathrm{c}))$. Fire also reduced offspring growth in medium $\left(\beta_{\text {Burned } \times \text { Medium harvest }}=-0.32 \pm\right.$ $0.081, \mathrm{Z}=-3.940)$ and in high $\left(\beta_{\text {Burned } \times \text { High harvest }}=-0.396 \pm 0.109, \mathrm{Z}=-3.618\right)$ harvest populations, in large gallery forest size $\left(\beta_{\text {Burned } \times \text { Habitat size }}=-0.126 \pm 0.058\right.$, $\mathrm{Z}=-2.174)$ and for individuals located far from the streambed $\left(\beta_{\text {Burned } \times \text { Distance to river }}\right.$ $=-0.15 \pm 0.033, Z=-4.530)$. Burned offspring grew better in 2017 than in 2016 $\left(\beta_{\text {Burned } \times 2017}=0.108 \pm 0.041, Z=2.626\right)$ despite the higher growth in 2017 than in $2016\left(\beta_{2016 \mathrm{vs} 2017}=-0.177 \pm 0.068, \mathrm{Z}=-2.614\right)$. In medium harvest populations, clonal offspring had higher growth than sexual offspring $\left(\beta_{\text {Mediumxclonal }}=0.229 \pm\right.$ $0.101, Z=2.272)$. In 2017 , offspring growth was lower in medium $\left(\beta_{2017 \times \text { Medium }}\right.$ harvest $=-0.492 \pm 0.038, Z=-12.874)$ and high $\left(\beta_{2017 \times \text { High harvest }}=-0.15 \pm 0.045, Z=\right.$ $-3.343)$ harvest populations. High harvest reduced growth in large gallery size ( $\beta_{\text {High harvest } \times \text { Habitat size }}=-1.146 \pm 0.475, \mathrm{Z}=-2.413$ ) and for offspring located far from the streambed $\left(\beta_{\text {High harvest } \times \text { Distance to riverbed }}=-0.245 \pm 0.104, \mathrm{Z}=-2.357\right)$. Clonal offspring also had higher growth in $2017\left(\beta_{\text {Clonal } 2017}=0.144 \pm 0.064, Z=\right.$ $2.263)$. In 2017 , growth was lower in large gallery forest size $\left(\beta_{2017 \times \text { Habitat size }}=\right.$ $-0.062 \pm 0.025, Z=-2.491$, Figure $3(\mathrm{c}))$ and for individual far from streambed $\left(\beta_{2017 \times \text { Distance to riverbed }}=-0.093 \pm 0.018, Z=-5.107\right.$, Figure $\left.3(\mathrm{c})\right)$.

\section{Discussion}

\subsection{Impact of Harvest, Habitat Size, Distance from Riverbed on the Regeneration Density across Ecological Regions}

Fire often reduced regeneration density [42]. Our study showed that fire can stimulate offspring density but the effect varied among years. For instance, on burned subplot, the offspring density decreased in 2016 and in 2017 whereas it was very higher in 2015. This may be due to the rescue effect of early rainfall. Indeed, we estimated density two or three months after late fire season. The allow to directly estimate dead offspring due to fire. It was after early rainfall which can rescue offspring from death. That was the case of our first year of study (2015). But, when the first rainfall came later, burned offspring die because of fire. Lower fire intensity can stimulate clonal reproduction from root.

Our result showed that high fruit harvest increased clonal ratio but reduced clonal recruitment. This is consistent with previous finding on P. butyracea [14] contrary to another study on the same species which showed that fruit harvest did not affect reproductive strategy [32]. The latter study was conducted only in moist region characterized by high rainfall, high humidity and high soil nutrient. This suggests that recurrent NTFPs harvest combined with other sources of disturbances such as habitat size reduction, fire and ecological conditions can reveal some effect which was unidentified with only one predictor. The reduction of 
clonal recruitment in high harvest population may suggest other stimulus of high clonal ratio. Fire may be the stimulus of clonal recruitment of tropical clonal tree species.

Our results also showed that fruit harvest in large gallery size limited clonal recruitment. In large gallery forest, humidity is often higher than in small gallery forest. High humidity can limit clonal recruitment [27]. This is consistent with the increase of clonal proportion with the increase of light and decreases with humidity [26] [28]. Also, the intensity of fire was reduced in large gallery forest. Soil nutrients are higher in large gallery forest than in small gallery forest regardless of ecological region. The negative interaction between habitat size and distance to streambed on clonal recruitment may suggest that despite of the determinant role of the soil nutrients in plant fertility and recruitment [22], clonal recruitment may not be directly related with soil quality.

\subsection{Effect of Fire, Gallery Forest Width and Fruit Harvest on Offspring Survival in Contrasted Ecological Regions}

Most studies on offspring survival focused on isolated effects of fire [43], NTFPs harvest [18], habitat size [19]) and fires [10]. Nevertheless, there was little attention on how the synergistic effect can mitigate the isolated effects of anthropogenic disturbances on demography [1] [16] [17]. Survival may be higher in large gallery forest size in presence of fire or in high harvest populations or be lower in small habitat size in the absence of fire or in low harvest populations as a synergistic response between predictors. We tested the interaction effect among population level habitat size using gallery forest width and individual level habitat size using distance to the streambed, the ecological region, fruit harvest, fires and reproduction strategy on survival.

Our results showed that survival was low in burned subplot in 2017. Indeed, high fire intensity can reduced survival [9] [10] due to heat injuries of roots, stem and crown [43] [44]. Recurrent fire causes xylem malfunction limiting nutrients conductivity which can lead to their mortality [45]. Survival was higher in high fruit harvest populations. Surprisingly, harvest mitigated the negative effect of large habitat size and an increase of distance to streambed on survival. In 2017, survival was lower in high harvest populations. Harvest of reproductive structures such as seeds and fruits does not directly affect offspring survival particularly when harvest does not involve killing individual [13]. In our study system, fires were common in low than in high harvested populations; such as Kpiti and Kota populations. This could prevent survival in the low harvest populations. Our results confirmed that since fire reduced $P$. butyracea offspring survival even if there is no significant interaction between harvest and fire. Contrary to our expectation, offspring survived better in small gallery forest size than in large gallery forest size and offspring located far from streambed survived better than those near the streambed in 2017. This may suggest the adaptation of offspring to small size and to local aridity. However, in the moist ecological region, offspring survived better in large gallery forest than in small gallery forest. 
Indeed, habitat size reduction increase individual mortality and thus species extinction risk [19]. Our results showed that it depends on ecological conditions.

\subsection{Effect of Fire, Gallery Forest Width and Fruit Harvest on Relative Growth Rate of $P$. butyracea Offspring in Moist and Dry Ecological Regions}

We found that in burned subplots of 2017, offspring growth was higher while their survival was lower suggesting a mediating effect of fire on growth and survival trade-off in burned subplots in 2017. A trade-off between growth and survival was found across species within sites for a subset of smaller plants within species with an evolutionary implication on reproduction size [46]. Consistent with empirical finding [11] [12]. Our results also showed that fire reduced $P$. butyracea offspring growth, suppressed the positive effect of large habitat size and amplified the negative effect of increasing local aridity on offspring growth. These findings highlight the role of fire in limiting tree growth even in large habitat size [47].

Fire and harvest synergistically reduced offspring growth whereas offspring growth was resilient to fire in moist ecological region suggesting that anthropogenic disturbances can synergistically affect offspring growth [48] and this can be mediated by ecological conditions. Moist ecological condition mitigated the negative effect of harvest and fire on growth. Surprisingly, offspring grew faster in dry region than in moist region. In 2017, offspring growth was higher in moist region. The variation of growth of seedling and sapling was highly stochastic in high perturbed environment and with year maybe due to the accumulated effect of disturbance and rainfall variation among year. Offspring growth was reduced in 2017 and in that year it was also reduced in large gallery forest than in small gallery forest. Contrary to the positive effect of light on seedling growth for light-dependent species [49], our results showed that the relative growth rate of offspring located far from streambed was low in 2017 and in large gallery than those near the streambed. This may suggest that $P$. butyracea offspring do not need enough light for their growth. Clonal offspring grew faster than sexual offspring in high harvest populations. In high harvest populations, clonal ratio was higher than seedling ratio [14] and clonal are connected to their mother and can benefit nutrient from them for their growth [30].

\section{Conclusion}

This study evaluated the effect of fire, habitat size, fruit harvest and distance to riverbed reduction on density, survival and growth of $P$. butyracea offspring across two contrasted ecological regions in the republic Benin. Results showed that increasing anthropogenic pressures especially fire and habitat size reduction can threaten $P$. butyracea persistence. The regeneration density and the recruitment are influenced by fire and their growth was reduced by fire even in large galleries. This suggests that fire should be prohibited in small gallery forests and controlled in large gallery forests. Fire prevention may reduce mortality [47]. 
The respect of forest legislation is required for sustainable management of $P$. butyracea and its habitat in order to limit agricultural pressure on gallery forests. It is necessary to set up a good conservation strategy for forest galleries based on environmental indicators, which are the indicators of fragmentation, diversity, structure and population demography for sustainability of the species. The results also showed that the effects of habitat size reduction and fire can be better understood, taking into account the environmental conditions as well as potential interactions between disturbances. Conservation and sustainable management of gallery forest, a fragile ecosystem must go through the respect of the forest legislation to limit the pressure of the agricultural on the forest gallery size. For a sustainable conservation of the populations of $P$. butyracea, gallery of small forests should be fully protected. The fire must be prohibited in small populations and be controlled in the large galleries. Ecosystem protection against fire can promote an abundance of regeneration and stability of population structure [24]. Testing how interaction of anthropogenic disturbances affect entire plant life cycle could allow to design optimal conservation strategy because demographic responses to disturbances can vary with individual size [50].

\section{Acknowledgements}

This work was financially supported by the International Foundation for Science (Grant $\mathrm{n}^{\circ} \mathrm{D} / 6092-1$ to MK). IDEA WILD provided equipment to MK. We are grateful to Julien Kouagou, Claude Kouagou, Béranger Medeton, Mohamed Bouko, Rodrigue N'Koué, N'Félikan Chicke, Edmond Abley and N'YamaSimbiafor field assistance.

\section{Conflicts of Interest}

The authors declare no conflicts of interest regarding the publication of this manuscript.

\section{References}

[1] Ticktin, T., Ganesan, R., Paramesha, M. and Setty, S. (2012) Disentangling the Effects of Multiple Anthropogenic Drivers on the Decline of Two Tropical Dry Forest Trees. Journal of Applied Ecology, 49, 774-784.

https://doi.org/10.1111/j.1365-2664.2012.02156.x

[2] Kagambega, F.W., Traore, S., Thiombiano, A. and Boussim, J.I. (2011) Impact of Three Soil Restoration Technique on Survival and Growth of Three Timber Species on "Zipellés" in Burkina Faso. International Journal of Biological and Chemical Sciences, 5, 901-914. https://doi.org/10.4314/ijbcs.v5i3.72174

[3] Haddad, N.M., Brudvig, L.A., Clobert, J., Davies, K.F., Gonzalez Holt, A.R.D. and Townshend, J.R. (2015) Habitat Fragmentation and Its Lasting Impact on Earth Ecosystems. Science Advances, 1, e1500052. https://doi.org/10.1126/sciadv.1500052

[4] Heithecker, T.D. and Halpern, C.B. (2007) Edge-Related Gradients in Microclimate in Forest Aggregates Following Structural Retention Harvests in Western Washington. Forest Ecology Management, 248, 163-173.

https://doi.org/10.1016/j.foreco.2007.05.003 
[5] Cochrane, M.A. (2003) Fire science for Rainforests. Nature, 421, 913-919. https://doi.org/10.1038/nature01437

[6] De Groot, W.J., Pritchard, J.M. and Lynham, T.J. (2009) Forest Floor Fuel Consumption and Carbon Emissions in Canadian Boreal Forest Fires. Canadian Journal of Forest Research, 39, 367-382. https://doi.org/10.1139/X08-192

[7] Devineau, J., Fournier, A. and Nignan, S. (2010) Savanna Fire Regimes Assessment with MODIS Fire Data: Their Relationship to Land Cover and Plant Species Distribution in Western Burkina Faso (West-Africa). Journal of Arid Environments, 74, 1092-1101. https://doi.org/10.1016/j.jaridenv.2010.03.009

[8] Dosso, K., Konate, S., Akoua, T. and Kouakou, M. (2011) The Study of Unburned Savanna Sections Serving as Temporary Refuges for Insects. An Experiment in a Tropical Humid Savanna in Côte D'Ivoire. Journal of Applied Biosciences, 39, 2607-2617.

[9] Ouédraogo, A., Thiombiano, A., Hahn-Hadjali, K. and Guinko, S. (2006) Sexual Regeneration of Boswellia dalzielii Hutch., a Medicinal Tree of High Value in Burkina Faso. Bois et Forêts Des Tropiques, 289, 41-48.

[10] Muoghalu, J.I. (2007) Tree Species Population Dynamics in a Secondary Forest at Ile-Ife, Nigeria after a Ground Fire. African Journal of Ecology, 45, 62-71. https://doi.org/10.1111/j.1365-2028.2006.00680.x

[11] Gignoux, J., Lahoreau, G., Julliard, R. and Barot, S. (2009) Establishment and Early Persistence of Tree Seedlings in an Annually Burned Savanna. Journal of Ecology, 97, 484-495. https://doi.org/10.1111/j.1365-2745.2009.01493.x

[12] Lawes, M.J., Adie, H., Russell-Smith, J., Murphy, B. and Midgley, J.J. (2011) How Do Small Savanna Trees Avoid Stem Mortality by Fire? The Roles of Stem Diameter, Height and Bark Thickness. Ecosphere, 2, 1-13. https://doi.org/10.1890/ES10-00204.1

[13] Ticktin, T. (2004) The Ecological Implications of Harvesting Non-Timber Forest Products. Journal of Applied Ecology, 41, 11-21. https://doi.org/10.1111/j.1365-2664.2004.00859.x

[14] Gaoue, O.G., Gado, C., Natta, A.K. and Kouagou, M. (2018) Recurrent Fruit Harvesting Reduces Seedling Density But Increases the Frequency of Clonal Reproduction in a Tropical Tree. Biotropica, 50, 69-73. https://doi.org/10.1111/btp.12486

[15] Farrington, S.J., Muzika, R.-M., Drees, D. and Knight, T.M. (2009) Interactive Effects of Harvest and Deer Herbivory on the Population Dynamics of American Ginseng. Conservation Biology, 23, 719-728. https://doi.org/10.1111/j.1523-1739.2008.01136.x

[16] Mandle, L. and Ticktin, T. (2012) Interactions among Fire, Grazing, Harvest and Abiotic Conditions Shape Palm Demographic Responses to Disturbance. Journal of Ecology, 100, 997-1008. https://doi.org/10.1111/j.1365-2745.2012.01982.x

[17] Mandle, L., Ticktin, T. and Zuidema, P.A. (2015) Resilience of Palm Populations to Disturbance Is Determined by Interactive Effects of Fire, Herbivory and Harvest. Journal of Ecology, 103, 1032-1043. https://doi.org/10.1111/1365-2745.12420

[18] Gaoue, O. and Ticktin, T. (2010) Effects of Harvest of Nontimber Forest Products and Ecological Differences on the Demography of African Mahogany. Conservation Biology, 24, 605-614. https://doi.org/10.1111/j.1523-1739.2009.01345.x

[19] Fahrig, L. (2003) Effects of Habitat Fragmentation on Biodiversity. Annual Review of Ecology and Systematics, 34, 487-515.

https://doi.org/10.1146/annurev.ecolsys.34.011802.132419 
[20] Bufford, J.L. and Gaoué, O.G. (2015) Defoliation by Pastoralists Affects Savanna Tree Seedling Dynamics by Limiting the Facilitative Role of Canopy Cover. Ecological Applications, 25, 1319-1329. https://doi.org/10.1890/14-0953.1

[21] Medjibe, V.P., Poulsen, J.R., Clark, C.J. and Mbani, O.A. (2014) Natural Regeneration of Selected Timber Species in the Republic of Congo. African Journal of Ecology, 52, 552-563. https://doi.org/10.1111/aje.12167

[22] Treurnicht, M., Pagel, J., Esler, K.J., Schutte-Vlok, A., Nottebrock, H., Kraaij, T. and Schurr, F.M. (2016) Environmental Drivers of Demographic Variation across the Global Geographical Range of 26 Plant Species. Journal of Ecology, 104, 331-342. https://doi.org/10.1111/1365-2745.12508

[23] Gaoue, O.G. and Ticktin, T. (2008) Impacts of Bark and Foliage Harvest on Khaya senegalensis (Meliaceae) Reproductive Performance in Benin. Journal of Applied Ecology, 45, 34-40. https://doi.org/10.1111/j.1365-2664.2007.01381.x

[24] Traoré, S., Kaboré, O., Rasolodimby, J.M., Thiombiano, L. and Guinko, S. (2008) Impact of Protected Areas and Land Use on Regeneration of Acacia Woodland's in Eastern Burkina Faso. Flora et Vegetatio Sudano-Sambesica, 11, 17-24.

[25] Ågren, J., Ehrlén, J. and Solbreck, C. (2008) Spatio-Temporal Variation in Fruit Production and Seed Predation in a Perennial Herb Influenced by Habitat Quality and Population Size. Journal of Ecology, 96, 334-345. https://doi.org/10.1111/j.1365-2745.2007.01334.x

[26] Lin, C.H., Miriti, M.N. and Goodell, K. (2016) Demographic Consequences of Greater Clonal than Sexual Reproduction in Dicentra canadensis. Ecology and Evolution, 6, 3871-3883. https://doi.org/10.1002/ece3.2163

[27] Klimešová, J. and Herben, T. (2015) Clonal and Bud Bank Traits: Patterns across Temperate Plant Communities. Journal of Vegetation Science, 26, 243-253. https://doi.org/10.1111/jvs.12228

[28] Herben, T., Šerá, B. and Klimešová, J. (2015) Clonal Growth and Sexual Reproduction: Tradeoffs and Environmental Constraints. Oikos, 124, 469-476. https://doi.org/10.1111/oik.01692

[29] Weppler, T., Stoll, P. and Stocklin, L. (2006) The Relative Importance of Sexual and Clonal Reproduction for Population Growth in the Longlived Alpine Plant Geum Reptans. Journal of Ecology, 94, 869-879. https://doi.org/10.1111/j.1365-2745.2006.01134.x

[30] De Kroon, H., Fransen, B., Rheenen, J.W.A., Van Rheenen, A., Van Dijk, A. and Kreulen, R. (1996) High Levels of Inter-Ramet Water Transport in Two Rhizomatous Carex Species, as Quantified by Deuterium Labeling. Oecologiaia, 106, 73-84. https://doi.org/10.1007/BF00334409

[31] Neuenschwander, P., Sinsin, B. and Goergen, G. (2011) Nature Conservation in West Africa: Red List for Benin. International Institute of Tropical Agriculture, Ibadan.

[32] Avocèvou-Ayisso, C., Sinsin, B., Adégbidi, A., Dossou, G. and Van Damme, P. (2009) Sustainable Use of Non-Timber Forest Products: Impact of Fruit Harvesting on Pentadesma butyracea Regeneration and Financial Analysis of Its Products Trade in Benin. Forest Ecology and Management, 257, 1930-1938.

[33] Avocèvou-Ayisso, C.M.A. (2011) Study of Pentadesma butyracea Sabine Population Viability and Their Socio-Economy in Bénin. PhD Thesis, University of Abomey-Calavi, Cotonou, 223 p.

[34] INSAE (2015) General Census of Population and Housing-Republic of Benin (RGPH 4). 
[35] Adomou, A.C. (2005) Vegetation Patterns and Environmental Gradients in Benin Implications for Biogeography and Conservation. Ph.D. Thesis, Wageningen University, Wageningen, $136 \mathrm{p}$.

[36] Bolker, B.M., Brooks, M.E., Clark, C.J., Geange, S.W., Poulsen, J.R., Stevens, M.H.H. and White, J.-S.S. (2009) Generalized Linear Mixed Models: A Practical Guide for Ecology and Evolution. Trends in Ecology and Evolution, 24, 127-135. https://doi.org/10.1016/j.tree.2008.10.008

[37] Brooks, M.E., Kristensen, K., van Benthem, K.J., Magnusson, A., Berg, C.W., Nielsen, A. and Bolker, B.M. (2017) glmmTMB Balances Speed and Flexibility among Packages for Zero-Inflated Generalized Linear Mixed Modeling. The R Journal, 9, 378-400. https://doi.org/10.32614/RJ-2017-066

[38] Bates, D., Maechler, M., Bolker, B. and Walker, S. (2015) Fitting Linear Mixed-Effects Models Using lme4. Journal of Statistical Software, 67, 1-48. https://doi.org/10.18637/jss.v067.i01

[39] Burnham, K.P. and Anderson, D.R. (2004) Multimodel Inference: Understanding AIC and BIC in Model Selection. Sociological Methods Research, 33, 261-304. https://doi.org/10.1177/0049124104268644

[40] Cribari-Neto, F. and Zeileis, A. (2010) Beta Regression in R. Journal of Statistical Software, 34, 1-24. https://doi.org/10.18637/jss.v034.i02

[41] R Core Team (2017) R: A Language and Environment for Statistical Computing. R Foundation for Statistical Computing, Vienna. https://www.R-project.org

[42] Ouédraogo, A. and Thiombiano, A. (2012) Regeneration Pattern of Four Threatened Tree Species in Sudanian Savannas of Burkina Faso. Agroforestry Systems, 86, 35-48. https://doi.org/10.1007/s10457-012-9505-9

[43] van Mantgem, P.J., Nesmith, J.C.B., Keifer, M., Knapp, E.E., Flint, A. and Flint, L. (2013) Climatic Stress Increases Forest Fire Severity across the Western United States. Ecology Letters, 16, 1151-1156. https://doi.org/10.1111/ele.12151

[44] Midgley, J., Lawes, M. and Chamaille-Jammes, S. (2010) Savanna Woody Plant Dynamics: The Role of Fire and Herbivory, Separately and Synergistically. Australian Journal of Botany, 58, 1-11. https://doi.org/10.1071/BT09034

[45] Michaletz, S.T. (2018) Xylem Dysfunction in Fires: Towards a Hydraulic Theory of Plant Responses to Multiple Disturbance Stressors. New Phytologist, 217, 1391-1393. https://doi.org/10.1111/nph.15013

[46] Metcalf, C.J.E., Horvitz, C.C., Tuljapurkar, S. and Clark, D.A. (2009) A Time to Grow and a Time to Die: A New Way to Analyze the Dynamics of Size, Light, Age, and Death of Tropical Trees. Ecology, 90, 2766-2778.

https://doi.org/10.1890/08-1645.1

[47] Groenendijk, P., Eshete, A., Sterck, F.J., Zuidema, P.A. and Bongers, F. (2012) Limitations to Sustainable Frankincense Production: Blocked Regeneration, High Adult Mortality and Declining Populations. Journal of Applied Ecology, 49, 164-173. https://doi.org/10.1111/j.1365-2664.2011.02078.x

[48] Zambrano, J. and Salguero-Gómez, R. (2014) Forest Fragmentation Alters the Population Dynamics of a Late-Successional Tropical Tree. Biotropica, 46, 556-564. https://doi.org/10.1111/btp.12144

[49] dos Santos, D.L., Rakocevic, M., Takaki, M. and Ribaski, J. (2006) Morphological and Physiological Responses of Cedrela fissilis Vellozo (Meliaceae) Seedlings to Light. Brazilian Archives of Biology and Technology, 49, 171-182. https://doi.org/10.1590/S1516-89132006000100020 
[50] Easterling, M.R., Ellner, S.P. and Dixon, P.M. (2000) Size-Specific Sensitivity: Applying a New Structured Population Model. Ecology, 81, 694-708.

https://doi.org/10.1890/0012-9658(2000)081[0694:SSSAAN]2.0.CO;2 